\title{
A Rare Bilateral Presentation of Multiple Dens Invaginatus, Shovel-Shaped Incisor and Talon Cusp With Mesiodens
}

\author{
Hegde S, Jain M, Shubha AB
}

Department of Paediatric Dentistry

Pacific Dental College and Hospital

Udaipur, Rajasthan, India

Corresponding Author

Sapna Hegde

Department of Paediatric Dentistry

Pacific Dental College and Hospital

Udaipur, Rajasthan, India

E-mail: drsapnahegde@yahoo.co.in

\begin{abstract}
The aim of this paper is to describe a unique and unusual case of concomitant appearance of morphological dental anomalies in the maxillary anterior region, along with its management in a patient with no systemic abnormality. This case report describes the clinical and radiographic features of talon cusp, dens invaginatus, shovel-shaped incisors and a supernumerary tooth occurring in a single patient, which is a rare presentation. All 4 permanent maxillary incisors had dens invaginatus, the permanent maxillary canines showed the presence of talon cusps, the permanent maxillary central incisors were shovel-shaped and an erupted mesiodens was also observed. Treatment included restorative, surgical and orthodontic approaches.
\end{abstract}

\section{KEY WORDS}

Dens invaginatus, developmental dental anomalies, talon cusp

\section{Citation}

Hegde S, Jain M, Shubha AB. A Rare Bilateral Presentation of Multiple Dens Invaginatus, Shovel-Shaped Incisor and Talon Cusp With Mesiodens. Kathmandu Univ Med J 2014;48(4):292-5.

\section{INTRODUCTION}

Morphological dental anomalies of the permanent teeth are seen to occur frequently; however, multiple anomalies in a single patient are relatively uncommon. The simultaneous occurrence of multiple abnormalities involving groups of teeth or the entire dentition may be genetically determined and can be associated with specific syndromes. ${ }^{1,2}$ Most arise sporadically and some, including those of shape and size, may be the result of environmental factors acting during the morphodifferentiation stage of tooth formation. ${ }^{3}$

The dental literature contains reports of concomitant occurrence of talon cusp and dens invaginatus, talon cusp, shovel shaped incisors and mesiodens and, dens invaginatus and mesiodens. ${ }^{4-9}$ No mention has been made, so far, of the occurrence of all 4 together in a single patient.

What follows is a report of an unusual concurrent occurrence of different morphological dental anomalies in several teeth of a single patient. It describes shovelshaped maxillary central incisors, bilateral dens invaginatus in permanent maxillary incisors, bilateral talon cusps in maxillary canines and mesiodens in a 14-year-old boy.

\section{CASE-REPORT}

A 14 year-old boy visited our pediatric dental service, with a complaint of mal-aligned front teeth. The past medical and family histories were not relevant.

The boy appeared well-nourished with a normal build. Intraoral examination (Fig. 1 and 2) revealed a permanent dentition with all teeth erupted up to the second molars. The molar relation was Angle's class I on the left side but not possible to determine for the right side because of a grossly destructed permanent mandibular right first molar. The lower anterior teeth were mildly crowded and maxillary 

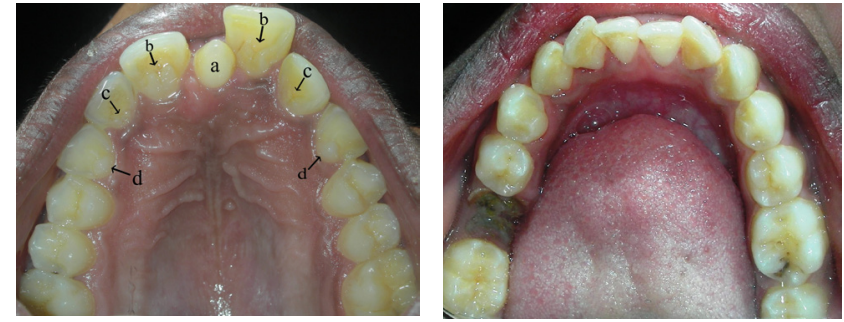

Figure 1. Intraoral occlusal view Figure 2. Intraoral occlusal of the maxillary arch showing a- view of the mandibular arch mesiodens, $b$ - dens invaginatus in shovel-shaped central incisors, cdens invaginatus in lateral incisors and $d$ - talon cusps on canines

anteriors proclined. The permanent maxillary right central incisor was deflected more labially in the arch (overjet = $10 \mathrm{~mm}$ ) than its counterpart on the left side (overjet $=6$ $\mathrm{mm}$ ) due to the presence of an erupted, conical mesiodens (Fig.3).

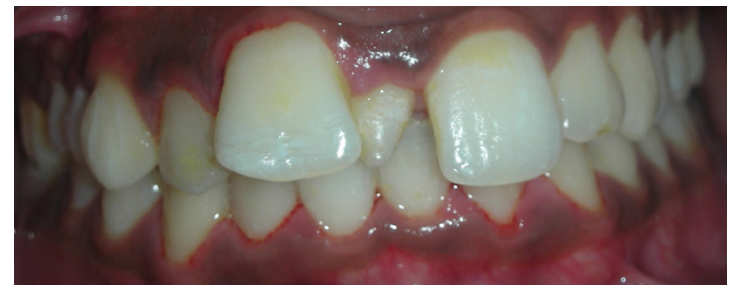

Figure 3. Labial view of the dentition

All 4 maxillary incisors exhibited deep lingual pits characteristic of dens invaginatus. The maxillary central incisors were shovel-shaped. The maxillary canines were observed to have prominent cingula which was consistent with the diagnosis of talon cusp type III (Hattabs classification). ${ }^{10}$ The anomalous cusps were not reported to interfere with speech, mastication or occlusion. A supernumerary tooth with a conical crown was seen between the maxillary central incisors positioned slightly closer to the right central incisor. The oral mucosa appeared normal with minimal inflammatory changes. Other intraoral findings included a grossly decayed mandibular right first permanent molar with resultant mesial drifting of the second molar and space loss. Initial distal class II caries was evident on the permanent maxillary left second premolar and class I caries on permanent mandibular left first molar.
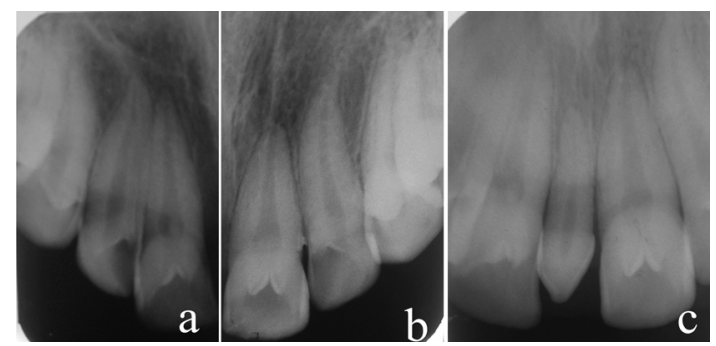

Figure 4. LIntraoral periapical radiograph showing a and b invagination of permanent maxillary central and lateral incisors and prominent cingulum of canine of the right and left sides, respectively; c - mesiodens with straight, conical root

Intraoral periapical radiograph (Fig. 4) of the maxillary incisors revealed radiopaque invaginations from the lingual

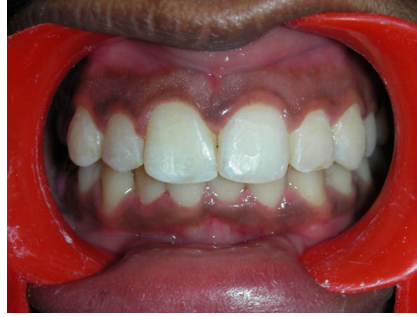

Figure 5. Post-treatment labial view of the dentition

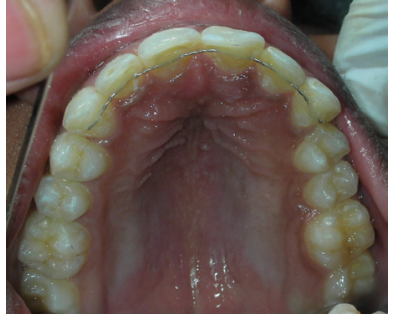

6. Post-treatment occlusal view of maxillary arch pits which were confined to the crowns of the teeth. These invaginations were of the enamel-lined minor form, within the confines of the crown and not extending beyond the cemento-enamel junction, which was consistent with the diagnosis of a dens invaginatus type I (Oehlers classification). ${ }^{11}$ The radiograph also showed the mesiodens as having a straight, tapered root. Intraoral periapical radiographs of the maxillary canines exposed the talon cusps as typical inverted cones with enamel and dentine layers and pulp horns extending only into the base of the cusps. The patient was clinically asymptomatic and none of these anomalies was associated with caries, gingivitis or loss of vitality.

In the present case, the palatal pits of the anterior teeth were sealed using composite resin. The maxillary left second premolar and mandibular left first molar were restored with composite resin. The mesiodens was extracted and the buccally-placed maxillary right central incisor was aligned using sectional fixed orthodontics followed by a fixed retainer. The space loss in the region of the mandibular right first permanent molar was regained using a modified NiTi space regainer and a removable prosthesis was placed (Fig. 5 and 6)

\section{DISCUSSION}

The concurrent existence of multiple dental anomalies has been reported previously, particularly in patients with chromosomal abnormalities who may present with multisystem abnormalities. ${ }^{12}$ Multiple dental anomalies have also been reported in patients without generalized abnormality or disease as in this case. An extensive review of the literature has revealed not a single case with a pattern of abnormalities similar to that seen in this patient.

Anomalies such as the talon cusp and dens invaginatus predominantly affect the maxillary incisor region, which is also the most frequent site for supernumerary teeth. Individually, the developmental dental abnormalities affecting the maxillary anterior region are wellcharacterized but their etiology remains unknown. These malformations are genetically determined because they are highly reproducible in shape, show predilection for some racial groups and often occur together. ${ }^{9}$ While these anomalies may sometimes compromise pulp vitality they are often asymptomatic incidental findings during routine clinical or radiographic examination, as in the current case. 
If not recognized early, premature tooth loss may result from communication with the pulp or predisposition to caries, resulting in pulp necrosis and periapical pathosis.

The talon cusp is an accessory cusp-like structure from the cingulum or cemento-enamel junction of maxillary or mandibular anterior teeth in either primary or permanent dentition. Studies have proved that the prevalence of the talon cusp varies considerably between ethnic groups, ranging from $0.06 \%$ in Mexican children to $7.7 \%$ in Indian children. ${ }^{13,14}$ A review of the dental literature suggests that $75 \%$ of talon cusps are seen in the permanent dentition, showing a higher frequency in males and a greater predilection for the maxilla. The maxillary lateral incisor is most often affected in the permanent dentition (67\%), followed by the central incisor (24\%) and canine (9\%). The anomaly is commonly unilateral but $1 / 5$ th of cases are bilateral in occurrence. ${ }^{10,15}$ In the present case, bilateral involvement of the canine was observed, which is a rare presentation.

Dens invaginatus is an enamel-lined cavity within a tooth. A dens invaginatus may occur in the coronal part of a tooth or rarely, within the root. The coronal form may range in extent from an incipient pit to significant invagination of the enamel with disruption of the coronal morphology and resulting in direct access for microorganisms between the pulp chamber and the oral cavity. The reported prevalence of adult teeth affected with dens invaginatus is between $0.3 \%$ and $10 \% .{ }^{16}$ Conflicting opinions exist regarding the clinical presentation of the anomaly with some investigators opining that it may be symmetrical, while others describe bilateral invaginations as a rare occurrence. ${ }^{17-20}$ The present case shows a bilateral occurrence with not just 2 but all 4 maxillary incisors involved.

Shovel-shaped incisors, so called because the lingual marginal ridges enclose a fossa, giving the appearance of a "coal shovel", have been considered a Mongoloid trait of the dentition. Shovelling of the incisors is considered

\section{REFERENCES}

1. Pindborg JJ. Pathology of the dental hard tissues. Munksgaard; 1970:15-73.

2. Hattab FN, Yassin OM, al-Nimri KS. Talon cusp - clinical significance and management: case reports. Quintessence Int 1995;26:115-20.

3. Bhussary BR, Sharawy M. Development and growth of teeth. In: Bhaskar SN. Orban's oral histology and embryology. $11^{\text {th }}$ ed, CV Mosby Co; 1990:44-8.

4. de Sousa SM, Tavano SM, Bramante CM. Unusual case of bilateral talon cusp associated with dens invaginatus. Int Endod J 1999; 32: 494-8.

5. Yadav M, Meghana SM, Kulkarni S. Concommitant occurance of dens invaginatus and talon cusp: A case report. Rev Odonto Cienc 2011; 26(2): 187-90.

6. Jimenez-Rubio A, Segura JJ, Jimenez-Planas A, Llamas R. Multiple dens invaginatus affecting maxillary lateral incisor and a supernumerary tooth. Endod Dent Traumatol 1997; 13: 196-8.

7. Oncag A, Gunbay S, Parlar A. William syndrome. J Clin Pediatr Dent 1995; 19: 301-4. to be a polygenic inheritable trait and differs considerably between groups of racial populations but is relatively stable within each group. Presence or absence of shovelling helps in racial identification and in exploration of ancestry. ${ }^{21}$ The incidence of shovelling in Saudi Arabians, Pakistanis and Indians is $10-12 \%$. The occurrence of invaginations in shovel-shaped incisors is $11 \% .^{22}$

Associations of the talon cusp with various anomalies have been reported occasionally in the dental literature such as that with mesiodens, dens invaginatus, supernumerary teeth, dens evaginatus of posterior teeth with palatal invagination or shovel-shaped incisors and hypodontia. ${ }^{5,6,8-10,23,24}$ But the concomitant occurrence of talon cusp, dens invaginatus, shovel-shaped incisors, and a supernumerary tooth has not yet been reported.

Clinical management of these anomalies varies from case to case. Treatment of dens invaginatus ranges from conservative restoration of the opening to endodontic treatment or extraction. ${ }^{25}$ Sequelae of undiagnosed and untreated invaginated teeth include pulp pathosis, eruption delay, cysts and internal resorption. ${ }^{26,27}$ The talon cusp may cause occlusal interference and trap plaque, predisposing to caries, periodontitis and trauma to the tongue. Attrition may expose the central pulp horn, so that conservative management, reduction, coverage and endodontic treatment may all play a role. Also, gradual periodic reduction of the cusp with fluoride as a desensitizing agent along with regular clinical and radiographic follow-up could be beneficial. ${ }^{2,6,10}$

\section{CONCLUSION}

Dental abnormalities such as those described above must be diagnosed early in order to prevent severe malocclusion and pulpal pathologies. Multidisciplinary approaches, followed by regular monitoring, are important.

8. Sharma A. Dens evaginatus of anterior teeth (talon cusp) associated with other odontogenic anomalies. J Indian Soc Pedod Prev Dent 2006; Special issue:S41-S43.

9. Lorena SC, Oliveira DT, Odell EW. Multiple dental anomalies in the maxillary incisor region. J Oral Sci 2003 45:47-50.

10. Hattab FN, Yassin OM, al-Nimri KS. Talon cusp in permanent dentition associated with other dental anomalies: review of literature and reports of seven cases. J Dent Child 1996;63: 368-76.

11. Ohelers FAC. Dens invaginatus (dilated composite odontome). Oral Surg Oral Med Oral Pathol 1957;10:1204-18.

12. McNamara CM, Garvey MT, Winter GB. Root abnormalities, talon cusps, dens invaginati with reduced alveolar bone levels: case report. Int J Paediatr Dent 1998;8:41-5.

13. Sedano HO, Freyre HC, Garza de la Garza ML, et al. Clinical orodental abnormalities in Mexica children. Oral Surg Oral Med Oral Pathol 1989;68:300-11.

14. Chawla HS, Tewari A, Gopalakrishnan NS. Talon's Cusp - A prevalence study. J Indian Soc Pedod Prev Dent 1983;1:28-34. 
15. Dankner E, Harari D, Rotstein I. Dens evaginatus of anterior teeth. Literature review and radiographic survey of 15,000 teeth. Oral Surg Oral Med Oral Pathol Oral Radiol Endod 1996 Apr; 81(4): 472-5.

16. Alani A, Bishop K. Dens invaginatus. Part 1: Classification, prevalence and aetiology. Int Endod J 2008;41:1123-36.

17. Hamasha AA, Al-Omari QD. Prevalence of dens invaginatus in Jordanian adults. Int Endod J 2004;37:307-10.

18. Grahnen H, Lindahl B, Omnell K. Dens Invaginatus. I. A clinical, roentgenological and genetical study of permanent upper lateral incisors. Odontologisk Revy 1959;10:115-37.

19. Swanson WF, McCarthy FM. Bilateral dens in dente. J Dent Res 1947;26:167-71.

20. Atkinson SR. The permanent maxillary lateral incisor. Am J Orthod 1943;29:685-98.

21. Hasegawa Y, Terada K, Kageyama I, Tsukada S, Uzuka S, Nakahara $\mathrm{R}$, Nakahara $\mathrm{S}$. Influence of shovel-shaped incisors on the dental arch crowding in Mongolian females. Okajimas Folia Anat Jpn 2009 Aug;86(2):67-72.
22. Kharat DU, Saini TS, Mokeem S. Shovel-shaped incisors and associated invagination in some Asian and African populations. J Dent 1990 Aug; 18(4): 216-20.

23. Acs G, Pokala P, Cozzi E. Shovel incisors, three rooted molars, talons cusp and supernumerary tooth in one patient. Pediatr Dent 1992; 14: 263-4.

24. Rao D, Hegde S. A talon cusp on fused tooth associated with hypodontia. Report of a unique case. Eur J Dent 2010; 4: 75-80.

25. Chaniotis AM, Tzanetakis GN, Kontakiotis EG, Tosios KI. Combined endodontic and surgical management of a mandibular lateral incisor with a rare type of dens invaginatus. J Endod 2008; 34: 1255-60.

26. Galindo-Moreno PA, Parra-Vázquez MJ, Sánchez-Fernández E, AvilaOrtiz GA. Maxillary cyst associated with an invaginated tooth: a case report and literature review. Quintessence Int 2003; 34: 509-14.

27. Mupparapu M, Singer SR. A review of dens invaginatus (dens in dente) in permanent and primary teeth: report of a case in a microdontic maxillary lateral incisor. Quintessence Int 2006; 37: 125-9. 